\title{
Septation During Sporulation in Streptomyces coelicolor
}

\author{
By H. WILDERMUTH* AND D. A. HOPWOOD \\ John Innes Institute, Norwich, NOR 7oF
}

(Accepted for publication 30 September 1969)

\begin{abstract}
SUMMARY
The fine structure of the morphological events during sporulation in Streptomyces coelicolor grown on chemically defined medium was studied in electron micrographs of thin sections. During vegetative growth the young hyphae were divided into long cells by cross-walls which formed in a way comparable to those in certain other Gram-positive bacteria. Sporulation was initiated by coiling of hyphal tips, which were then divided into sporesized compartments by special cross-walls, the 'sporulation septa'. These were laid down as double rings attached to the hyphal wall and extending centripetally. After completion of the septa the walls thickened uniformly and the individual spores began to round off. The new wall material on the long side of the spores appeared to be deposited underneath the old parent wall; the old cell wall probably formed part of the spore wall.
\end{abstract}

\section{INTRODUCTION}

New information about sporulation in Streptomycetes became available during the last decade when thin sections were studied in the electron microscope. According to Glauert \& Hopwood (I96I) sporulation in Streptomyces coelicolor begins by separation of the hyphal wall into an outer and inner layer. Annular ingrowths from the inner layer then extend towards the centre of the hypha to divide it into spore-sized units. The inner parent wall, together with the new septum material, constitutes the wall of the young spore, to which further layers are added as the spore matures. Rancourt \& Lechevalier (I964) and Bradley \& Ritzi (I968) came to similar conclusions for $S$. viridochromogenes and $S$. venezuelae respectively.

The aim of the present study was to obtain more information about the morphological changes during spore formation in wild-type Streptomyces coelicolor as a prerequisite for a study of the genetic control of sporulation, a morphogenetic problem which is being investigated in this laboratory by the study of mutants defective in sporulation (Hopwood, Wildermuth \& Palmer, 1969). Since the lesion in many of the mutants is in the division of the aerial hyphae into spore-sized units, attention was focused on this process in the wild-type.

\section{METHODS}

The strain was wild-type A3(2) of Streptomyces coelicolor (S. violaceoruber) according to Kutzner \& Waksman (1959). Stock cultures were maintained on a complex medium ('complete medium' of Hopwood, I967). Well sporulating colonies were grown on plates of chemically defined 'minimal medium' (Hopwood, 1967) incubated at $30^{\circ}$. Colonies were fixed on the second day after the appearance of

* Present address: Zoologisches Institut der Universität Zürich, 8006 Zürich, Switzerland. 
a grey-brown coloration on the aerial mycelium; such colonies contained all stages of sporulation, including mature spores (Wildermuth, 1969). The colonies were cut out of the medium on small blocks of agar and prepared for electron microscopy as described in an accompanying paper (Wildermuth, 1969).

\section{RESULTS}

The developmental steps in spore formation could not be experimentally synchronized in a growing culture as can be done in Bacillus (see for example Ryter, 1965). This, and the fact that the colonies of filamentous Streptomycetes are morphologically complex, made structural analysis of the process more difficult; in sections and impressions of sporulating aerial mycelium all the different stages of spore formation occurred together. A prerequisite for the present work was therefore a study of the development and spatial organization of the colonies (Wildermuth, 1969) which aided the reconstruction of the developmental sequence in spore formation.
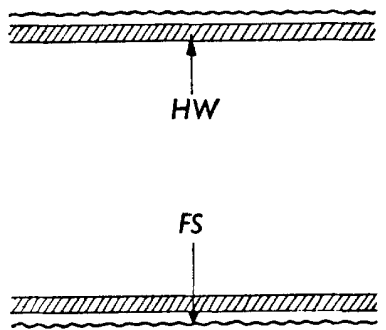

(a)
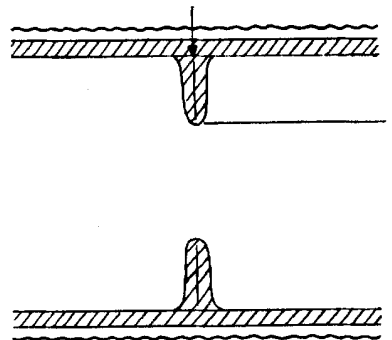

(b)

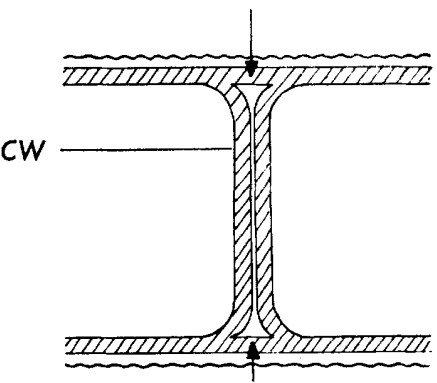

(c)

Fig. I. Diagram of cross-wall formation in an aerial hypha. At the start of the process (a) the cell envelope consists of the hyphal wall $(H W)$ and the fibrous sheath $(F S)$. New wall material is deposited $(b)$ in the form of an annulus of double thickness, separated at first from the old hyphal wall by a dark line (arrow). Later $(c)$ the cross-wall fuses with the old hyphal wall, leaving a piece of old wall material (arrow); the cross-wall $(C W)$ is now distinctly double.

Cross-wall formation in vegetative aerial hyphae. Although this process is not part of sporulation it provided a comparison for the morphologically different septation in aerial hyphal tips that led to the formation of spores. Stages in cross-wall formation were only rarely observed. The process was initiated by annular ingrowth of a double layer of wall material, beginning at the inside of the old hyphal wall (Pl. I, fig. I). First (Fig. I) the young cross-wall was separated from the old hyphal wall by a dark line (Pl. I, fig. I, and Fig. I $b$ : arrow); later the new cross-wall fused with the original hyphal wall, leaving a spare piece of old wall material which sometimes broke when the cells rounded off slightly at their ends. The cross-walls separating adjacent cells were double (Pl. I, fig. I, 2; Pl. 2, fig. 3); this doubtless accounts for the fact that the aerial hyphae can fragment into viable single cells able to initiate new colonies (Hopwood, I960). The cross-walls appeared in unbranched regions of the hyphae, but also frequently at branch points (P1. 2, fig. 3); branching without septation was also found.

The lengths of cells in the aerial hyphae were measured in negatively stained 
preparations in which cross-walls were clearly visible. Non-apical cells of sporulating hyphae were 3 to $16 \mu \mathrm{m}$. long, while the apical cells of young hyphae which had not yet begun to sporulate were much longer; some could be followed for $50 \mu \mathrm{m}$. without showing any cross-walls. It is believed that young aseptate hyphae were divided intolong segments by hyphal cross-walls, the apical cells subsequently being partitioned into shorter units $(\mathrm{I} \cdot 5$ to $2 \cdot 0 \mu \mathrm{m}$.), each of which gave rise to a spore. The actual length of sporulating apical cells could not, however, be determined since in negatively
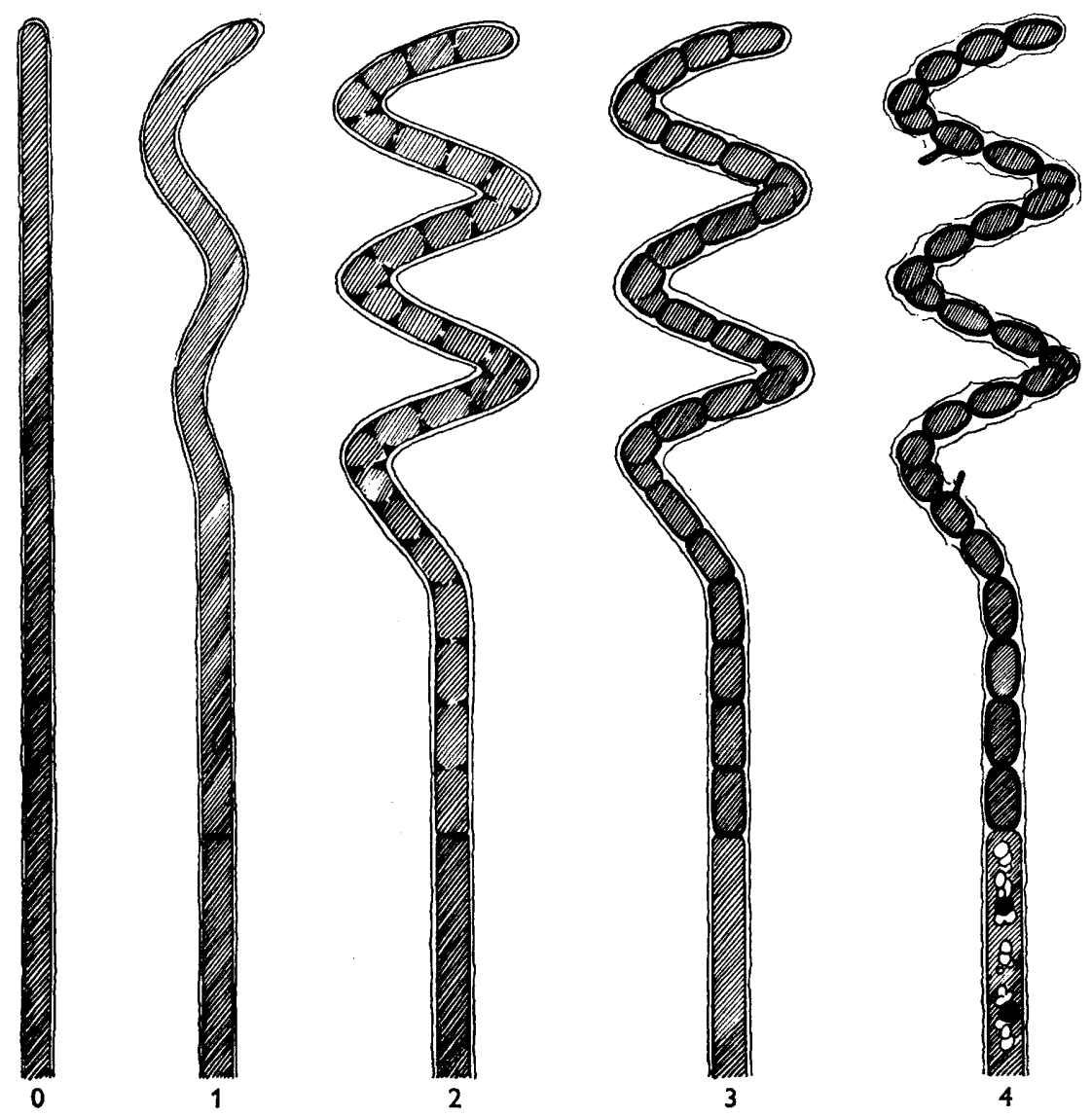

Fig. 2. Diagram of sporulation stages in Streptomyces coelicolor. After a phase of growth (o) the sporulating hyphae are divided into long cells by ordinary cross-walls and the tips begin to coil (I). The apex is then partitioned into spore-sized compartments by sporulation septa (2). The cell walls thicken and constrictions appear between the young spores (3). As spores mature, they round off and separate (4). Some spores begin to germinate immediately after maturation.

stained specimens it was not possible to distinguish between the hyphal cross-walls and the septa which divided the cells into spore-sized compartments. Therefore it was not certain whether sporulation was confined to apical cells or occurred also in sub-apical ones.

Fine structural changes during spore formation. The steps in sporulation are represented diagrammatically in Fig. 2; they have been classified into a number of stages 
as in Bacillus subtilis (Ryter, 1965) and Clostridium histolyticum (Bayen, Frehel, Ryter \& Sebald, 1967 ).

Thin sections of aerial mycelial cells at stage 0 are shown in P1. 2, fig. 3. The typical features of such cells were described by Glauert \& Hopwood (1959, 1960, I96I) and Hopwood \& Glauert (1960 $b$ ) and are briefly summarized here. The cell wall $(C W)$, which had the appearance characteristic of a Gram-positive wall, was overlain by the superficial fibrous sheath $(F S)$. The interior of each cell was bounded by the plasma membrane $(P M)$ and was occupied by membranes of the mesosome system $(M)$, 'vacuoles' $(V)$, and fibrous nuclear material $(N)$ mainly in long zones corresponding with the elongated chromatic bodies seen in the light microscope (Hopwood \& Glauert, 1960a); ribosomes, which presumably would have been revealed by lead staining, were barely visible in these sections because of their low contrast.

Plate 3, fig. 4 represents a longitudinal section of a hypha which had coiled at stage $I$ and was therefore ready for the formation of the special 'sporulation septa'. The nucleoplasm was still in long zones, which only later became divided into smaller portions, each allocated to one spore compartment. The orientation of the nuclear fibrils was not random; as noted by Hopwood \& Glauert (1960 b), most of the fibrils ran longitudinally in some regions of the hyphae and transversely in others.

At stage 2 (Pl. 3, fig. 5 and Pl. 4, fig. 6) the sporulation septa (SS) were formed at regular intervals, their development being synchronized over a certain length of hypha. Each septum developed as a double annulus growing towards the centre of the hypha. The two adjacent layers of the septum were separated from the beginning by a gap which was very obvious at the inner edge of the annulus (Pl. 3, fig. 5, arrow). At the same time the nuclear material $(N)$ appeared to be constricted at the sites of the growing spore septa (Pl. 3, fig. 5) and was fully divided just before the septa were completed ( $\mathrm{Pl}$. 4, fig. 6). Occasionally, the young septa could be seen to be accompanied by mesosomes, but usually these were more obvious at the next stage of spore formation (Pl. 4 , fig. $7, M$ ). Sections through the top of the aerial mycelium of a colony revealed few early stages of septum formation, but many later stages; hence septation must have been rapid. The hyphal wall at stages I and 2 always consisted of one layer, still Io to $\mathrm{I} 2 \mathrm{~nm}$. thick; the double-layered hyphal wall described by Glauert \& Hopwood (196I) was not observed.

Late stage 2 (2b) (Pl. 4, fig. 7 and Pl. 5, fig. 8) was characterized by completed septum formation. Whereas in early stage 2 (2a) there was more material at the base of the septa than on their inner edge, at the end of the process the septa were uniformly thick and each layer of the double septum was no thicker than an average hyphal wall (IO to I $2 \mathrm{~nm}$.). Spore wall material was initially deposited on the long sides of spore walls only at the margin of the sporulation septa, where a boundary between the spore wall material and the old hyphal wall could be identified (Pl. 3, fig. 5, B). Later, after completion of the septa, new wall material was gradually added to the septum and to the inner side of the parent hyphal wall. These processes led to stage 3, which is defined by a thickened wall ( 20 to $25 \mathrm{~nm}$.) and the appearance of marginal constrictions between the spore compartments (Pl. 6, fig. 9). Sometimes the spore compartments also began to separate centrally and were then held together by only a thin annulus consisting of the old parent wall (Pl. 6, fig. 9, $P W$ ) and the fibrous sheath $(F S)$, a thin superficial layer which surrounded the aerial hyphae and 
spores (Hopwood \& Glauert, 196I). Except where adjacent spores abutted, it was difficult to distinguish between the old hyphal wall and the new spore wall: the only detached layer was the superficial fibrous sheath.

Structures in the interior of the cell appeared indistinct at this stage; in most sections it was not even possible to identify the nuclear material. Mesosomes were only rarely found and the cytoplasm was full of vacuoles with ill-defined boundaries and of very low electron density (Pl. 6, fig. 9: $P$ ). At stage 4 the spores were mature (PI. 6, fig. Io and Pl. 7, fig. II) and were held together by only a fragile envelope consisting of the fibrous sheath and disintegrating parts of the old hyphal wall; the chains easily broke into separate spores. The spore wall had reached its final thickness ( 30 to $50 \mathrm{~nm}$.). The mature spores were very hard and consequently were extremely difficult to section; most of the spores were folded during cutting. Cytoplasm and nuclear material looked much the same as at stage 3 . Mesosomes were found in both sections and negatively stained preparations of spores.

In colonies just beginning to sporulate a number of newly formed spores were already germinating (Wildermuth, 1969). In negatively stained impressions of such colonies germinating spores were even found within chains of spores. In sections of young colonies many spores appeared better preserved (Pl. 7, fig. I2). It seems likely that these spores were germinating (although the germ tube was not seen in the section) or at least in a preparative stage for the process.

The spore wall occasionally appeared multilayered, this being more obvious in germinating spores which mostly exhibited two distinct layers. However since the stratification showed great variation it must be interpreted with caution (see Discussion).

\section{DISCUSSION}

This study of thin sections of the aerial mycelium of Streptomyces coelicolor has revealed two different processes of cross wall formation, one occurring in vegetative aerial hyphae and the other in sporulating hyphal tips. The difference between these two processes has been confirmed in a study of mutants defective in sporulation (Hopwood et al. 1969); some classes of mutants are unable to form the sporulation septa but produce normal cross walls in the aerial hyphae and in the substrate mycelium.

The cross-walls in the non-sporulating aerial hyphae (and probably also in the substrate hyphae) were formed in the manner typical of Gram-positive bacteria, as for example in Bacillus (Glauert, I962; Ellar, Lundgren \& Slepecky, 1967): by annular deposition of new wall material centripetally. In Bacillus the young wall is about twice as thick as the normal cell wall; it splits after completion and the daughter cells separate. In the filamentous Streptomycetes the adjacent cells normally did not separate, but could be separated artificially; the isolated hyphal cells were viable and able to initiate new colonies (Hopwood, I960). In sections of both complete and unfinished cross-walls a dark central line could be seen. This boundary was not observed in young cross-walls of Bacillus (see for example Ellar et al. 1967) but was found in Microbacterium thermosphactum (Davidson, Mobbs \& Stubbs, I968).

In contrast to the hyphal cross-walls the sporulation septa were deposited synchronously over a certain range at regular short intervals. The wall material was less compact in the beginning, wider at its base and regularly split at the inner edge of the 
annulus. This unusual behaviour for bacterial cross-walls was also found in Streptomyces venezuelae (Bradley \& Ritzi, 1968) but not in Streptomyces viridochromogenes (Rancourt \& Lechevalier, 1964).

According to Glauert \& Hopwood (I96I) the parent hyphal wall separated into an outer and an inner latter, the latter extending towards the centre of the cell by annular ingrowth, thus forming the spore septum. This new cross-wall together with the inner parent wall constituted the young spore wall to which more material was added as the spore matured. Rancourt \& Lechevalier (1964) and Bradley \& Ritzi (1968), who studied sporulation in Streptomyces viridochromogenes and in Streptomyces venezuelae respectively, followed essentially Glauert and Hopwood's interpretation. However it is doubtful whether such a behaviour of the parent hyphal wall can be deduced from their micrographs, which show fewer details than those of Glauert \& Hopwood (I96I).

1
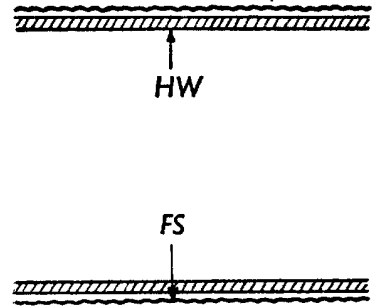

2(a)
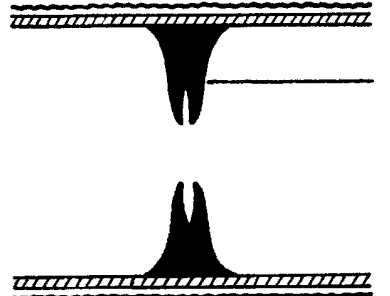

2(b)

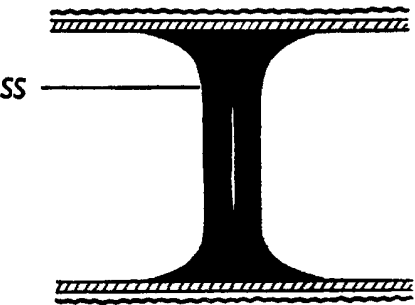

3

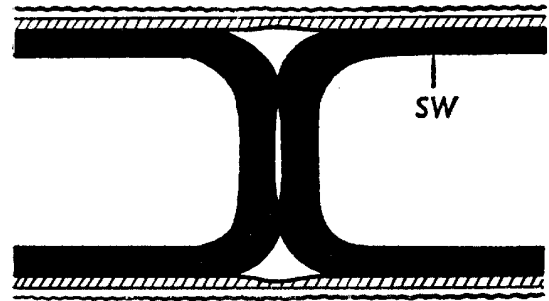

4

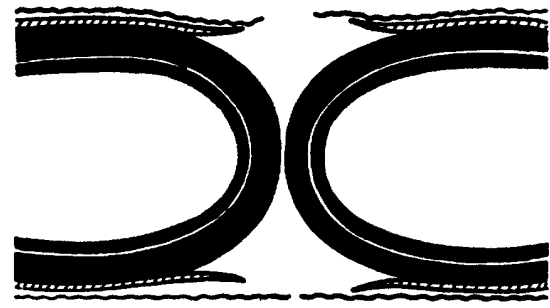

Fig. 3. Diagram of spore-wall formation. At the beginning of sporulation (Stage I) the cell envelope consists of the hyphal wall $(H W)$ and the fibrous sheath $(F S)$. During stage 2 the sporulation septa $(S S)$ are formed. At stage 3 the future spore-wall $(S W)$ is laid down. While the spores round off and begin to separate, they are maturing (stage 4 ) and the spore-wall is still thickening.

In the sections described in this paper the separation of the parent hyphal wall into an outer and an inner layer by a dark line could not be confirmed and the thickness of the wall remained the same until completion of the cross-wall. According to these findings it is believed that the material of the future spore walls was deposited inside the parent hyphal wall, and probably a completely new coat was synthesized for the spore (Fig. 3). However the old hyphal wall presumably remained attached to the spore and formed part of the wall, leaving detached ends only at the site of the sporulation septa. A clear boundary between the old and the new wall was not generally seen. Therefore Streptomyces spores cannot be considered as endospores, especially since all the nuclear material and cytoplasm was included in the spore, in 
contrast to the situation in Bacillaceae and to the recently discovered situation in certain thermophilic actinomycetes (Cross, Walker \& Gould, I968).

The walls of the mature spores seemed to be multilayered; several distinct layers were described by Hagedorn (1960) in Streptomyces griseus and by Glauert \& Hopwood (I96I) in Streptomyces coelicolor. In the present study the walls of 'resting' spores occasionally exhibited two layers. In germinating spores, whose walls were apparently softer, the stratification was more obvious. However it was less clear than in Bacillus (Ryter, 1965, Ellar \& Lundgren, 1966, Leadbetter \& Holt, I968) or Clostridium (Hoeniger, Stuart \& Holt, 1968, Bayen et al. 1967) and probably depends on factors such as fixation, sectioning and the physiological state of the spore. Therefore these structures have to be interpreted with caution. The same applies to the interior of mature spores which appeared smooth and without any details. This is seen in all spore-forming bacteria so far examined, including Actinomycetes (Dorokhorva, Agre, Kalakoutskii \& Krassilnikov, I968), but it remains possible that this is due to insufficient penetration of the fixative and stains.

The mesosomes, which were conspicuous during sporulation, behaved as in other spore-forming bacteria: they were associated with the young septa. Like the other structures they became less clear during the late stages of sporulation, but they definitely persisted in spores. This could be demonstrated not only in germinating spores (Mach, 1965) but also in sections (Pl. 7, fig. II) and negatively stained preparations of 'resting' mature spores.

Part of this work was carried out at the Institute of Genetics, University of Glasgow. It is a pleasure to thank Audrey M. Glauert for her helpful criticisms of the manuscript during its preparation.

\section{REFERENCES}

Bayen, H., Frehel, C., Ryter, A. \& Sebald, M. (1967). Etude cytologique de la sporulation chez Clostridium histolyticum: souche sporogene et mutants de sporulation. Annales de l'Institut Pasteur, Paris I13, 163.

Bradley, S. G. \& Ritzi, D. (I968). Composition and ultrastructure of Streptomyces venezuelae. Journal of Bacteriology 95, 2358.

Cross, T., WALKer, P. D. \& Gould, G. W. (I968). Thermophilic actinomycetes producing resistant endospores. Nature, London 220, 352.

Davidson, C. M., Moвbs, P. \& Stubss, J. M. (1968). Some morphological and physiological properties of Microbacterium thermosphactum. Journal of Applied Bacteriology 31, 55I.

Dorokhova, L. A., Agre, N. S., Kalakoutskit, L. V. \& Krassilnikov, N. A. (1968). Fine structure of spores in a thermophilic actinomycete, Micromonospora vulgaris. Journal of General and Applied Microbiology, Tokyo 14, 295.

Ellar, D. J. \& LundGren, D. G. (I966). Fine structure of sporulation in Bacillus cereus grown in a chemically defined medium. Journal of Bacteriology 92, 1748.

Ellar, D. J., Lundgren, D. G. \& Slepecky, R. A. (1967). Fine structure of Bacillus megaterium during synchronous growth. Journal of Bacteriology 94, I 189.

Glauert, A. M. (1962). Fine structure of bacteria. British Medical Bulletin r8, 245.

Glauert, A. M. \& Hopwood, D. A. (1959). A membranous component of the cytoplasm in Streptomyces coelicolor. Journal of Biophysical and Biochemical Cytology 6, 515 .

GlauerT, A. M. \& Hopwood, D. A. (1960). The fine structure of Streptomyces coelicolor. I. The cytoplasmic membrane system. Journal of Biophysical and Biochemical Cytology 7, 479.

GlautrT, A. M. \& Hopwood, D. A. (196I). The fine structure of Streptomyces violaceoruber (S. coelicolor). III. The walls of the mycelium and spores. Journal of Biophysical and Biochemical Cytology 10, 505 . 
HAGEDORN, H. (1960). Elektronenmikroskopische Untersuchungen an Streptomyces griseus (Krainsky). Zentralblatt für Bakteriologie, Parasitenkunde, Infektionskrankheiten (Abteilung II) 113, 234.

Hoeniger, J. F. M., Stuart, P. F. \& Holt, S. C. (I968). Cytology of spore formation in Clostridium perfringens. Journal of Bacteriology $96, \mathrm{I} 8 \mathrm{I} 8$.

Hopwood, D. A. (1960). Phase-contrast observations on Streptomyces coelicolor. Journal of General Microbiology 22, 295.

Hopwood, D. A. (1967). Genetic analysis and genome structure in Streptomyces coelicolor. Bacteriological Reviews 3x, 373.

Hopwood, D. A. \& Glauert, A. M. (1960a). Observations on the chromatinic bodies of Streptomyces coelicolor. Journal of Biophysical and Biochemical Cytology 8, 257.

Hopwood, D. A. \& Glauert, A. M. (1960 b). The fine structure of Streptomyces coelicolor. II. The nuclear material. Journal of Biophysical and Biochemical Cytology 8, 267.

Hopwood, D. A. \& GlaukRT, A. M. (1961). Electron microscope observations on the surface structures of Streptomyces violacoeruber. Journal of General Microbiology 26, 325.

Hopwood, D. A., Wildermuth, H. \& Palmer, H. M. (1969). A morphogenetic system in Streptomyces coelicolor. Heredity, London 24, 517.

KutZNER, H. J. \& WAKSMAN, S. A. (1959). Streptomyces coelicolor Müller and Streptomyces violaceoruber Waksman \& Curtis, two distinctly different organisms. Journal of Bacteriology 78, 528.

LeAdbetter, E. R. \& Holt, S. C. (1968). Fine structure of Bacillus fastidiosus. Journal of General Microbiology 52, 299.

MACH, F. (1965). Die Substruktur keimender Streptomyces-Sporen Zeitschrift für allgemeine Mikrobiologie 5, 267.

Rancourt, M. W. \& Lechevalier, H. A. (1964). Electron microscopic study of the formation of spiny conidia in species of Streptomyces. Canadian Journal of Microbiology ro, 3 I I.

Ryter, A. (1965). Etude morphologique de la sporulation de Bacillus subtilis. Annales de l'Institut Pasteur, Paris 108, 40.

Wildermuth, H. (1970). Development and organisation of the aerial mycelium in Streptomyces coelicolor. Journal of General Microbiology 6o, 43.

\section{EXPLANATION OF PLATES}

Electron micrographs of thin sections of Streptomyces coelicolor aerial hyphae and spores. The scale mark represents $0.25 \mu \mathrm{m}$.

\section{Plate I}

Fig. I. Cross-wall formation in an aerial hypha during the vegetative phase. The arrow indicates the boundary between the outer cell wall and the young cross-wall.

Fig. 2. Longitudinal section through a vegetative part of an aerial hypha, showing the double complete cross-wall. Note the gap $(G)$ within the double wall. $M$, mesosome.

\section{Plate 2}

Fig. 3. Section through vegetative aerial hyphae, showing the typical features of a Streptomyces cell. $C W$, cell wall; $F S$ fibrous sheath; $M$, mesosome; $N$, nuclear material; $P M$, plasma membrane; $V$, vacuole. Note the double cross-wall.

Plate 3

Fig. 4. Longitudinal section through an aerial hypha at sporulation stage I. The cell is curved and the nucleoplasm $(N)$ forms an elongated body.

Fig. 5. Aerial hypha at early sporulation stage 2 (2a). The sporulation septum (SS) appears as a double annulus, showing a gap at the growing margin (arrow). The nucleoplasm is constricted at the site of the septum. Note the boundary between the old parent wall and the septum material $(B)$.

Plate 4

Fig. 6. Stage 2a, showing a spore compartment bounded by two sporulation septa. The left septum appears almost complete because it was tangentially sectioned. The nuclear bodies $(N)$ appear to be completely separated.

Fig. 7. Late stage 2 (2b). The sporulation septa are complete. Note the mesosomes $(M)$ associated with a newly formed septum. 

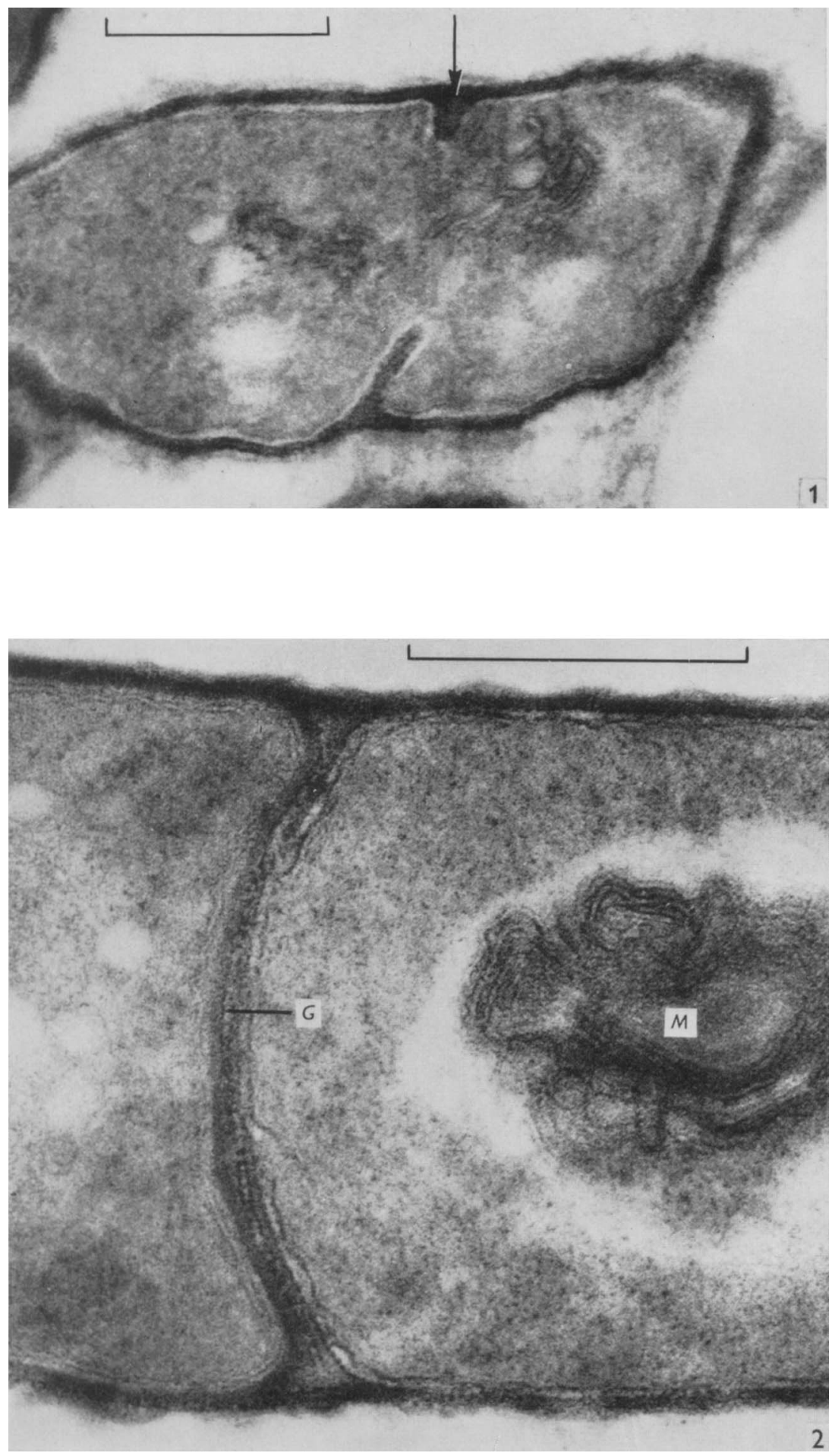


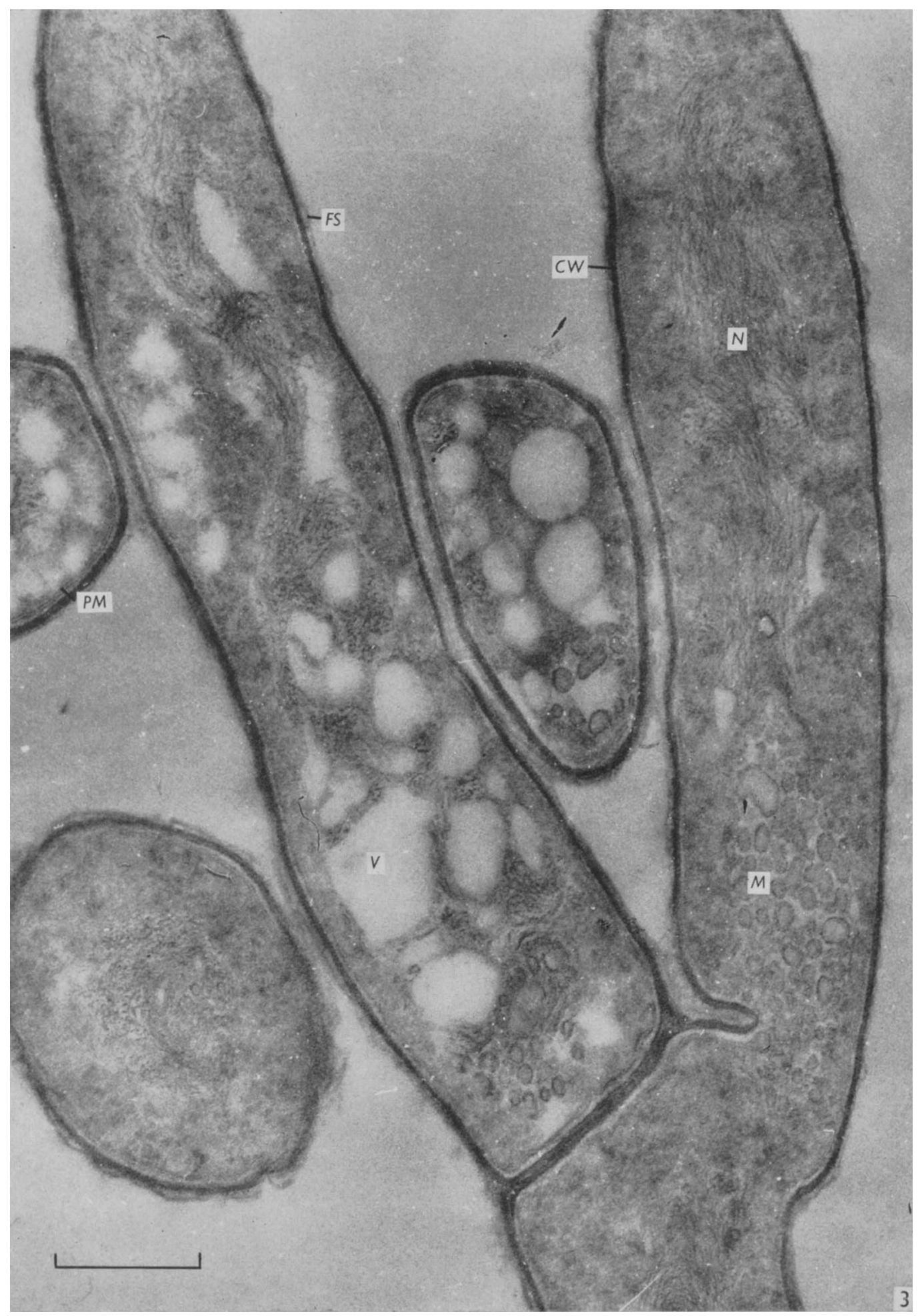


Journal of General Microbiology, Vol. 6o, No. I

Plate 3
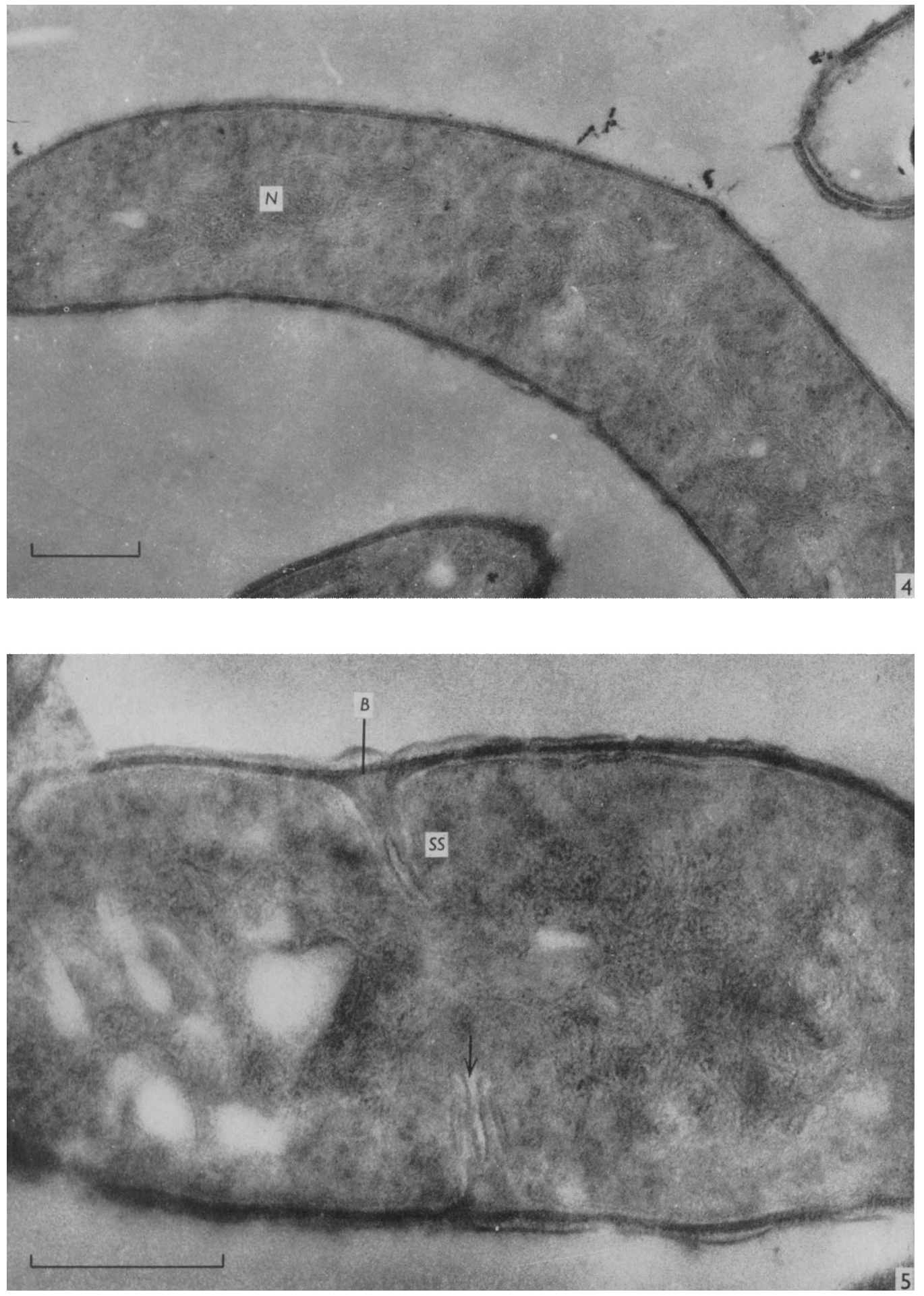

H. WILDERMUTH AND D. A. HOPWOOD 
Journal of General Microbiology, Vol. 6o, No. I

Plate 4
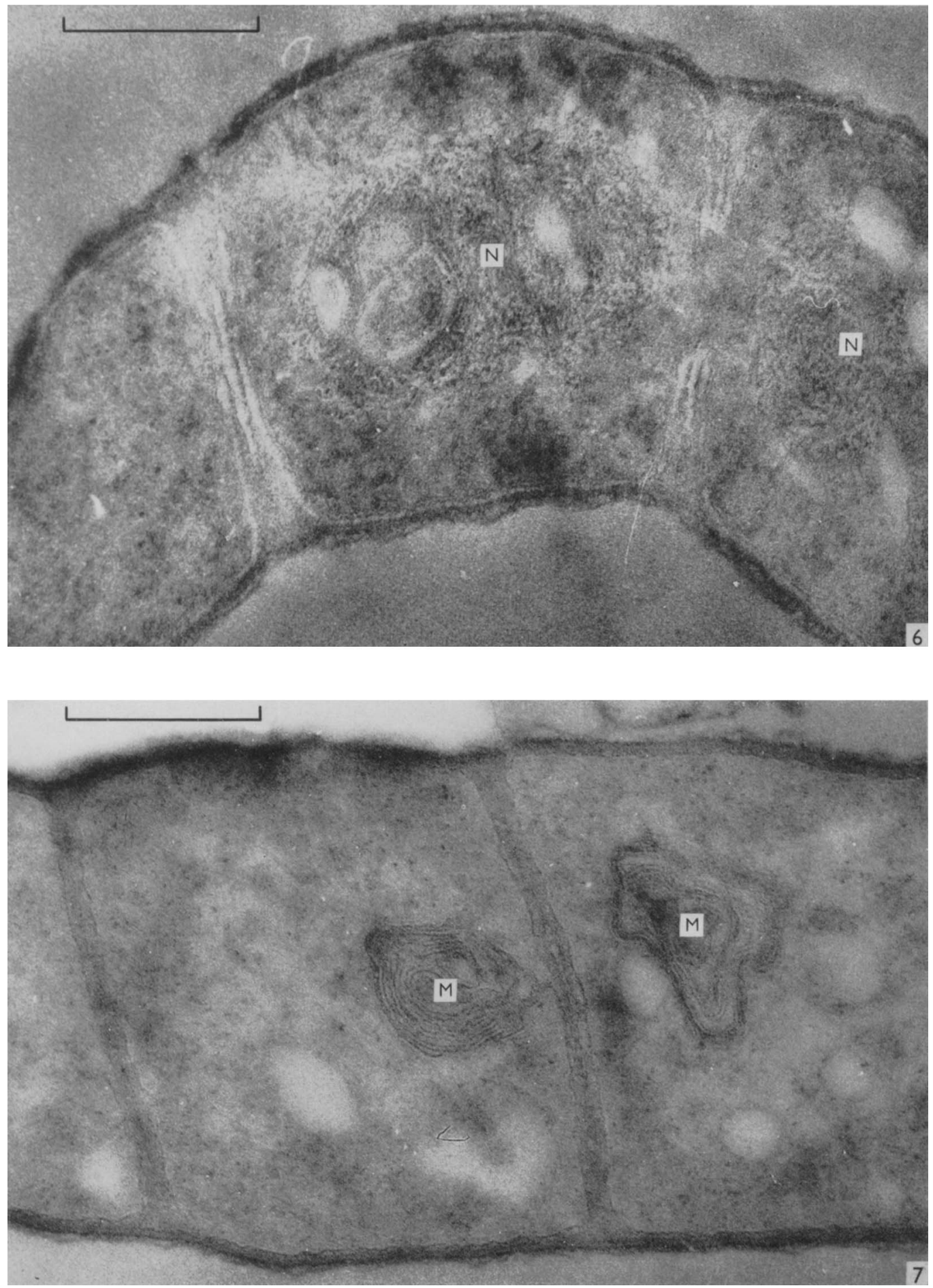

H. WILDERMUTH AND D. A. HOPWOOD 


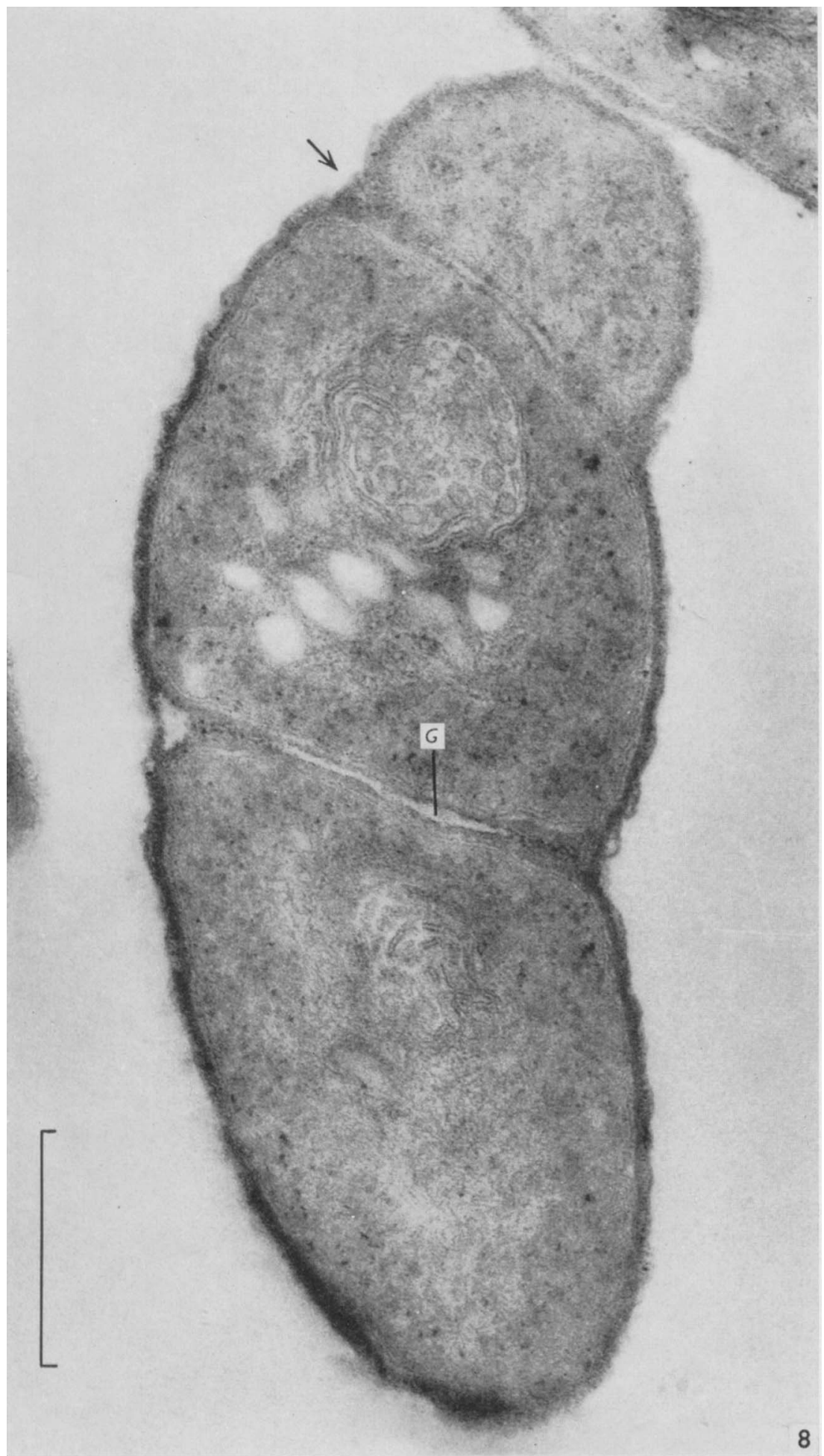

H. WILDERMUTH AND D. A. HOPWOOD 

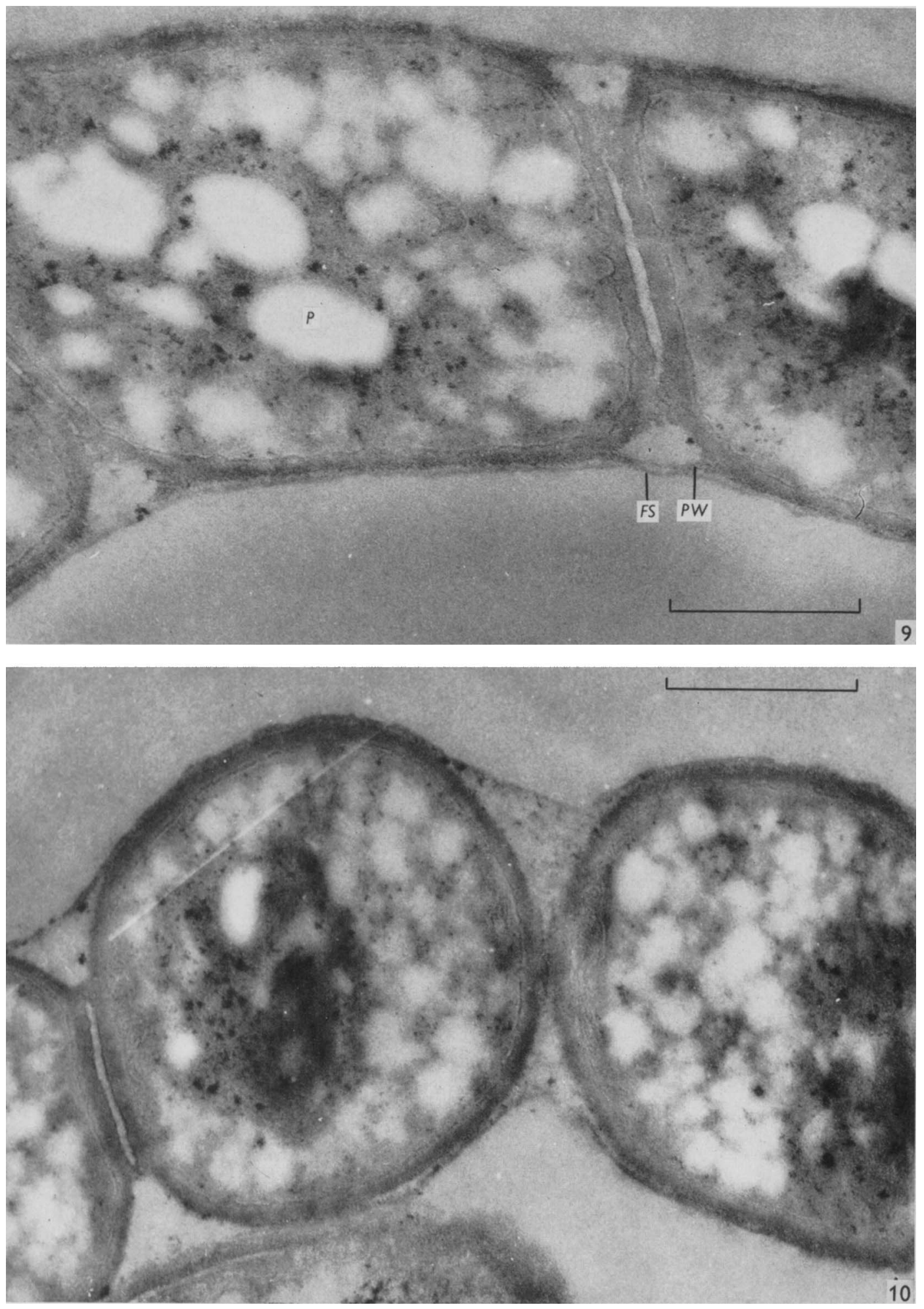

H. WILDERMUTH AND D. A. HOPWOOD 



H. WILDERMUTH AND D. A. HOPWOOD 


\section{Plate 5}

Fig. 8. Stage $2 b$, showing the double septa. The gap $(G)$ and rounding corners (arrow) indicate the transition to stage 3 .

\section{Plate 6}

Fig. 9. Stage 3. The spore wall has noticeably thickened from $\mathrm{I} 2$ to about $25 \mathrm{~nm}$, and the individual spores, which are still held together by remnants of the parent hyphal wall $(P W)$ and the fibrous sheath $(F S)$, begin to round off. The contents of the cell appear blurred with vacuole-like patches $(P)$. Fig. Io. Part of a chain of maturing spores (stage 4).

\section{Plate 7}

Fig. II. Typical features of a mature spore. The mesosome $(M)$ in this specimen is exceptionally well visible.

Fig. I2. Mature spore, probably before or during germination. Details such as nucleoplasm and plasma membrane are better preserved than in the specimen shown in fig. II. The spore-wall appears double-layered. 